\title{
Os conflitos de licenciandos e o desenvolvimento profissional docente ${ }^{*}$
}

Vânia G. Massabni

Universidade de São Paulo

Correspondência:

Vânia G. Massabni

R. João Sampaio, 1620, ap. 51

13416-383 - Piracicaba/SP

massabni@esalq.usp.br

* Agradecimentos à contribuição da Profa. Dra. Cilene Ribeiro de Sá Leite Chakur (UNESP - Araraquara) na leitura inicial do projeto de pesquisa, na arbitragem das histórias hipotéticas e nas sugestões ao manuscrito deste artigo.

\section{Resumo}

Aprender a ensinar requer o desenvolvimento de atitudes, valores e conhecimentos próprios da docência por parte dos futuros professores, constituindo-se em um processo complexo a ser desencadeado pelas licenciaturas. Este estudo parte da premissa de que o licenciando vivencia conflitos ao longo de tal processo, os quais são possivelmente agravados pelas mudanças que a profissão docente tem sofrido, mudanças estas que, para alguns, configuram uma crise. Estudos anteriores, apoiados na teoria de Jean Piaget, indicam que a forma de perceber e resolver conflitos por professores em exercício é diferente entre os sujeitos, e que nem sempre o modo de lidar com as situações profissionais está relacionado ao tempo de carreira, mas sim a níveis de construção da docência. Assim, buscou-se saber se existem conflitos entre os professores em formação e se a forma de resolvê-los relaciona-se à aquisição da profissionalidade. Para tanto, licenciandos responderam a questionário e entrevista a partir de histórias hipotéticas envolvendo situações potencialmente geradoras de conflitos relativos a questões como autoridade docente, autonomia profissional e escolhas pedagógicas, entre outras. A compreensão da forma como os licenciandos interpretavam e enfrentavam - ou não - tais conflitos ofereceu indícios de níveis de construção da profissionalidade pelos sujeitos, mesmo que ainda não formados. Reconhecer a existência desses níveis abre caminhos para repensar a formação de professores nas licenciaturas, a fim de que se propiciem condições para que o licenciando desenvolva-se a um patamar superior de profissionalidade ainda durante a formação inicial.

\section{Palavras-chave}

Conflito - Prática educativa - Licenciatura - Desenvolvimento profissional. 


\section{The conflicts of licentiateship students and teachers professional development}

Vânia G. Massabni

University of São Paulo

Contact:

Vânia G. Massabni

R. João Sampaio, 1620, ap. 51 13416-383 - Piracicaba/SP massabni@esalq.usp.br

* The author wishes to thank Dr. Cilene Ribeiro de Sá Leite Chakur (UNESP, Araraquara) for the initial reading of this research project, for the refereeing of hypothetical stories, and for her suggestions to the manuscript of this article.

\section{Abstract}

Learning to teach requires on the part of the future teachers the development of attitudes, values, and knowledges proper to the teaching activity, constituting a complex process that has to be put in motion by the licentiateship courses. The present study starts from the premise that the licentiateship student experiences conflicts during this process, which are possibly intensified by the changes that the teaching profession has undergone, changes that for some configure a crisis. Previous studies, based on Jean Piaget's theory, indicate that the ways to perceive and resolve conflicts vary among working teachers and that the way to deal with professional situations is not always related to career time, but to levels of construction of the teaching activity. Thus, the study sought to find out whether there are conflicts among teachers in preparation, and if the way to solve them can be related to the acquisition of professionalism. To that end, licentiateship students responded to a questionnaire and an interview based on hypothetical stories involving situations that were capable of producing conflicts related to issues such as teacher authority, professional autonomy, and pedagogical choices, among others. Understanding how the licentiateship students interpreted and dealt with - or failed to deal with - such conflicts offered clues as to the levels of construction of professionalism by the subjects, even if they had not yet concluded their courses. To recognize the existence of these levels opens up ways to rethink teacher education in licentiateships, so as to offer conditions for the students to develop further, into a higher level of professionalism, still during their initial training.

\section{Keywords}

Conflict - Educative practice - Licentiateship - Professional development. 


\section{A aprendizagem da docência na licenciatura}

Os alunos de um curso de licenciatura têm uma certeza: ao final do curso, se forem bem-sucedidos, receberão um diploma que confere habilitação especial para o exercício profissional da docência. Como afırma Selma Garrido Pimenta (2002), para além da finalidade de conferir uma habilitação legal, espera-se que o curso de formação inicial forme o profissional colaborando para o início da docência, afinal, essa formação continuará ao longo do exercício da profissão (IMBERNÓN, 1994). Por outro lado, a formação docente inicia-se muito antes da licenciatura, pois, segundo Maurice Tardif (2002), os professores iniciam sua aprendizagem na vivência pré-profissional, cuja força permanece forte e estável ao longo do tempo, dificultando que a maioria dos dispositivos da formação inicial seja sufıciente para modificar as crenças elaboradas nesse percurso.

Maria da Graça Mizukami (2000) afirma que aprender a ensinar pode ser considerado um processo complexo, que inclui experiências anteriores, fatores afetivos, cognitivos e éticos, entre outros. Professores desenvolvem uma forma de ser e estar no mundo, uma identidade profissional, adquirindo conhecimentos, habilidades, atitudes e valores que influenciarão seu ensino e a formação das gerações a serem educadas por ele. Ser professor vai muito além de uma atividade em que bastaria saber qual a técnica pedagógica mais adequada a uma situação de ensino, ou dominar o conhecimento específico de uma área ou disciplina, complexidade nem sempre compreendida ao longo de um curso de formação inicial.

Cabe lembrar que, no Brasil, os cursos de licenciatura têm passado por revisão, fruto, em parte, de alterações na legislação, cujos impactos ainda têm sido analisados (DIAS-DA-SILVA; MUZZETI, 2006), e dos questionamentos sobre a efetividade desses cursos. Caracterizada pela desvinculação tanto entre teoria e prática educativa, uma vez que a prática é relegada apenas aos estágios localizados no final dos cursos, quanto entre licenciatura e bacharelado, pois geralmente os cursos organizam-se pelo modelo conhecido como 3+1 - três anos de disciplinas especificas do bacharelado acoplados a um ano dedicado às disciplinas pedagógicas (DIAS-DASILVA; MUZZETI, 2006) -, a formação torna-se fragmentada e possivelmente frágil. Segundo Francisco Imbernón (1994), o formato desses cursos é tributário de um modelo de formação que privilegia a transmissão acadêmica de conhecimentos, segundo a ótica de que basta saber bem o conteúdo e ter algum conhecimento pedagógico, de preferência obtido na prática, para saber ensinar, de modo que a formação fica alijada de seus componentes não técnicos, como os sociopolíticos e contextuais, essenciais para a docência.

As pesquisas realizadas sobre a formação e o trabalho docente, que tomam a prática pedagógica como referência, têm auxiliado na elaboração de outra concepção de formação. De acordo com Imbernón (1994), a proposta de formação orientada ao questionamento da prática leva a um novo modelo que rejeita o papel do professor como transmissor de conteúdos e/ou técnico especialista em prol de um papel mais ativo no desenho e na reformulação de estratégias e programas de intervenção educativa. Segundo o autor, tal modelo está apoiado na racionalidade prática.

Conforme afirma Kenneth Zeichner (1993), a preocupação com uma formação reflexiva e investigativa da prática está na base dessa redefınição e vem sendo provocada pela influência de estudos que tomam o professor como um prático reflexivo e construtor de saberes a partir da investigação da própria prática. 0 autor considera haver também um novo modelo para que se estabeleça a relação entre teoria e prática nos cursos, em que cada sujeito deve iniciar com uma reflexão sobre a própria experiência. É necessária uma formação construída por um trabalho de reflexão crítica daquilo que é feito nas práticas educativas, a qual implica um investimento pessoal 
com vistas à construção de uma identidade (NÓVOA, 1992).

Entende-se, no presente estudo, que, nessa ótica de formação, um dos compromissos das licenciaturas seria o de auxiliar o futuro professor a desenvolver-se profissionalmente ainda como aluno, oferecendo condições para que conhecimentos, habilidades, atitudes e valores, bem como uma identidade profissional, sejam elaborados e continuem a desenvolver-se após o término do curso.

Busca-se entender como se constrói a profissionalidade docente no momento dos estágios da licenciatura, profissionalidade esta que se manifesta na forma de conceber e desempenhar as diversas funções da profissão - ensinar, orientar o estudo, ajudar individualmente, regular relações, preparar materiais, saber avaliar, organizar espaços e atividades etc. (GIMENO SÁCRISTÁN, 1995). Uma profissionalidade desenvolvida, para Imbérnon (1994), ou profissionalidade ampla, nos termos de Lawrence Stenhouse, é caracterizada, entre outros aspectos, pela capacidade de relacionar experiências das aulas com a política e as metas educacionais, bem como de comparar metodologias dos professores à sua própria. Assim, desenvolver amplamente a profissionalidade requer assumir um compromisso sociopolítico, relacionando-o à sua função em sala de aula.

0 desenvolvimento profissional, no entanto, não se dá sem conflitos e desvios de rotas que configuram trajetórias pessoais na docência - pessoais, mas possivelmente com similaridades, como pensamos existir. 0 presente estudo é proposto no esteio daqueles desenvolvidos por Cilene Chakur (2001, 2002, 2005), que entende haver uma lacuna nas investigações sobre o desenvolvimento profissional docente, pois estas são orientadas a compreender as fases desse desenvolvimento por uma ótica que se embasa em um simples desenrolar cronológico. Tais estudos, dos quais a autora cita os de Huberman e Cavaco, delimitam fases da docência caracterizadas por tempo de profissão, identificando tendências comuns no percurso profissional da maioria dos professores em exercício. Para Chakur (2002), faltam investigações que indiquem de que forma esse desenvolvimento ocorre, desvendando mecanismos cognitivos reguladores que expliquem os percursos profissionais e justifiquem os desvios de rota vividos por professores.

Chakur $(2001,2005)$ recorre à teoria construtivista piagetiana para buscar pistas nessa compreensão, caracterizando formas de enfrentamento dos conflitos e sua relação com o desenvolvimento profissional em professores experientes. Resta saber quais são os conflitos e como eles se relacionam com o desenvolvimento profissional quando este é ainda incipiente - como no caso do professor em formação.

Quando deparam, pela primeira vez, com a realidade da escola - e da sala de aula -, é que podem emergir muitos dos conflitos a serem enfrentados pelos licenciandos. Quais são os conflitos vividos por eles nesse processo, durante a graduação? Como os cursos de licenciatura podem auxiliar esses futuros professores a instrumentalizarem-se, de forma teórica e prática, para enfrentar - ou ao menos tolerar - os conflitos? Existem novos conflitos que emergem de uma configuração nova da profissão, tida por alguns como em crise? Foram essas questões que nos motivaram a conduzir o presente estudo.

\section{Os conflitos/dilemas na formação de professores}

Para realizar o estudo, inicialmente buscamos informações sobre o universo de trabalho e as funções que o profissional deve desempenhar na escola básica, pois quem se prepara para um trabalho pode ter conflitos gerados por inseguranças e dúvidas sobre como atuar nas condições concretas da profissão. Compreender o desenvolvimento profissional requer imaginar como se desempenha determinada profissão. E, para formar professores e entender seus conflitos, temos que compreender o que se passa com a profissão 
docente, pois as dificuldades de ser professor hoje em dia podem gerar inseguranças e frustrações. Entre os desafios, está o crescimento do número de alunos e de sua heterogeneidade sociocultural, a demanda por educação de qualidade para a população, o surgimento de novas metodologias, além de, conforme afırma Bernadete Gatti (1996), a educação estar imersa em uma estrutura institucional hierárquica e burocrática e não ser, na prática, prioridade dos governantes. Segundo essa autora, é por conta desses desafios que a profissão de professor vem sofrendo profundas transformações nos países em desenvolvimento, como o Brasil.

Outros autores (VILLA, 1988; IMBERNÓN, 1994) também creditam a desorientação da função docente às mudanças sociais, especialmente à explosão escolar ocorrida em diversos países nas décadas de 1960 e 1970, e à presença maciça dos meios de comunicação. Acrescentamos que tais mudanças podem ser também percebidas pelo aumento de informações circulantes e pela visão economicista presente na educação, por exemplo, quando esta é encarada como estando a "serviço dos clientes” (NÓVOA, 1995, p. 9).

Um dos desafios à função docente é o questionamento, que não é recente, do papel do professor como transmissor do conhecimento, o que colabora na configuração de uma crise profissional (VILLA, 1988). Critica-se a visão do professor como autoridade que deve transmitir seus conhecimentos a uma plateia inculta, ao mesmo tempo em que faltam referências sobre qual seria seu papel, já que outras propostas ${ }^{1}$ não são incisivas quanto à importância do professor no processo de ensino e aprendizagem, e até mesmo questionam seu papel em uma escola tida, por vários estudos, como instituição que mais reproduz do que modifica a sociedade.

Outros desafios à profissão podem ser enumerados, como a perda de prestígio profis-

1- São exemplos discussões sobre o papel do professor diante de propostas que valorizam o emprego das novas tecnologias e de propostas construtivistas em que caberia a ele apenas o papel de facilitador ou orientador da aprendizagem, conforme apontamos em outro estudo (MASSABNI, 2005). sional, de status social e econômico, e de reconhecimento social da especificidade requerida para ensinar, sendo uma grande fonte de stress para os professores o sentimento de que não dominam as situações e os contextos de intervenção profissional (NÓVOA, 1995). Além disso, seu trabalho é intensificado com a sobrecarga de tarefas (APPLE, 1995), pois a profissão tem-se tornado mais burocrática, viabilizando que o professor torne-se apenas um executor ou aplicador de técnicas, materiais e projetos pensados por outras instâncias em um contexto de políticas neoliberais.

Esses aspectos citados da profissão, entre outros que aqui não caberia aprofundar, podem estar despertando ou agravando os conflitos naqueles que pretendem seguir, ou ao menos se preparam, para a profissão docente. Assumir a docência como profissão é ter que decidir por querer ensinar sem saber se dará conta desses desafios.

0 estudo sobre os conflitos, como o aqui apresentado, pauta-se na compreensão de que o ensino é tarefa problemática, pois requer conviver com inseguranças e dúvidas que geram conflitos para os quais muitas vezes não existem respostas únicas, corretas ou precisas, e perante os quais é preciso optar por uma solução. Segundo Tardif (2002), o professor, durante a aula ou fora dela, está fazendo escolhas e gerenciando dilemas a todo momento, e, por isso, pode-se dizer que tensões e dilemas, negociações e estratégias de interação são inerentes ao trabalho docente

Magdalene Lampert (1985) entende o professor como um negociador de dilemas, constantemente submetido a eles na medida em que precisa resolver, diariamente, se, em determinado momento, repreende um aluno que não faz a tarefa, preocupando-se com as consequências ao futuro pessoal e profissional da criança, ou permite que ela se desvie momentaneamente para uma atividade não-escolar, mais prazerosa, conforme discutem Ann Berlak e Harold Berlak (1981), como forma de negociar seu posterior engajamento na atividade. Dilemas como 
favorecer a socialização em detrimento da individualização, a equidade em detrimento da excelência, e a educação geral em detrimento da especialização são insolúveis, segundo Miriam Ben-Peretz e Lya Kremer-Hayon (1990), pois têm que ser reavaliados a cada situação em que emergem. Para José Gimeno Sacristán (1995),

o cerne do processo educativo reside na escolha de modelos de desenvolvimento humano, na opção entre diversas respostas face às características dos grupos e contextos sociais. (p. 87)

Ele também advoga que, por isso, o professor é um gestor de dilemas. Para o autor, as ações de formação de professores podem ampliar a consciência dos problemas educacionais e dos modelos alternativos, trabalhando o desenvolvimento do pensamento profissional dilemático.

Um dilema pode ser uma tensão permanente do professor quando este busca um objetivo (em si, inalcançável); o dilema pode ser entendido como uma busca insistente na ação docente. Por exemplo, o professor pode estar sempre com a preocupação de inserir temas, por iniciativa das crianças, que façam parte do conteúdo, ou pode estar pensando na necessidade de mantê-las envolvidas na tarefa apresentada em aula, por meio da motivação (ZABALZA, 2004). Miguel Zabalza (2004) mostra como é possível identificar os dilemas dos professores a partir do estudo de seus diários, compreendendo-os como ferramentas conceituais para a análise da atuação docente, pois dão conta da complexidade da aula.

Quando emprega o conceito de dilema, Zabalza (2004) refere-se a "todo o conjunto de situações bipolares ou multipolares que se oferecem ao professor no desenvolvimento de sua atividade profissional" (p. 18), sendo um exemplo de dilema o ajuste das exigências de programas oficiais às necessidades específicas dos alunos. Segundo o autor, trata-se de situações problemáticas (pontuais ou gerais) em que é necessário optar por um dos polos do dilema, opção que nem sempre se faz de forma consciente.

Por outro lado, Chakur (2001) esclarece que

uma situação de conflito não se liga, necessariamente, à atuação efetiva, nem depende fundamentalmente do contexto, a menos que o contexto seja concebido como aquilo que o professor consegue perceber. (p. 215)

Tal situação pode ser, assim, de ordem cognitiva e não contextual. Para o conceito de dilema - ou das situações dilemáticas -, a atuação e o contexto em que ocorrem são fundamentais; o dilema é situado. Assim, optamos pelo conceito de conflito em vez do de dilema, o que nos auxilia a embasar uma abordagem construtivista piagetiana para o estudo: o desequilíbrio gerado na mente do sujeito fica evidente no conflito por ele relatado.

0 conflito é o elemento perturbador do equilíbrio atingido pelo sujeito em certo momento, sendo gerado por um jogo de pressões que levam a um impasse no qual o sujeito está diretamente envolvido (CHAKUR, 2001). Para Jean Piaget (1976), perceber algo como um problema causa perturbação às estruturas mentais do sujeito. Uma perturbação pode ou não levar ao desequilíbrio dessas estruturas e o sujeito recorre a reações compensatórias, que são formas de compensar os efeitos da perturbação e reequilibrar-se. Simplificadamente, as reações são de três tipos:

- conduta Alfa: pode-se negar o problema, evitando perceber o potencial perturbador da situação (o desequilíbrio mantém-se), e podendo ocorrer a deformação da situação na tentativa de assimilar o fator perturbador às estruturas já existentes, àquilo que é familiar, de modo a continuar pensando como antes; 
- conduta Beta: diante do problema ou obstáculo, o sujeito não busca anulá-lo, negando-o, mas modifica o esquema disponível a fim de conseguir ajustá-lo à situação;

- conduta Gama: pode-se tentar a antecipação, o que permite superar o desequilíbrio causado.

$\mathrm{Na}$ antecipação, podem-se fazer tentativas de acomodação das novas informações e ativar esquemas anteriores, integrando-os ou diferenciando-os de modo que as respostas à perturbação sejam dedutíveis, o que evita que o problema novamente se constitua como obstáculo. Tende-se chegar a um novo equilíbrio, o que nos leva a um patamar superior de desenvolvimento.

Também a ideia de centração/descentração presente na teoria piagetiana ajuda-nos a compreender o desenvolvimento profissional docente, pois, segundo tal teoria, o desenvolvimento do sujeito requer a descentração das causas aparentes de certos resultados. Para Chakur (2005), a distinção entre fazer (ou saber fazer) e compreender, e o papel da tomada de consciência são elementos da teoria piagetiana que auxiliam na compreensão do desenvolvimento profissional. Segundo a autora, Piaget (1997) quando aborda a tomada de consciência, considera que toda atividade humana exige algum grau de consciência - a qual pode ser elementar ou periférica - quando se aplica a dados imediatamente percebidos, aos objetivos da ação ou aos resultados constatados como êxito ou fracasso. A consciência, para atingir a compreensão, recorre à tomada de consciência. Ela vai da periferia para o centro, onde a centralidade do problema - e a compreensão do como e do porquê - depende de reflexões sobre os meios empregados e suas correções.

Pode ser que o licenciando veja uma situação como obstáculo superável, percebendo-a como um conflito para o qual é possível buscar soluções e ações coerentes do sentido da superação ou da convivência com o conflito. Nessa convivência, o futuro professor resolve temporariamente o conflito, conforme avalia o que o contexto requer, pois, assim como discutido em relação aos dilemas, nem sempre se chega a uma solução definitiva. Quando o licenciando enxerga obstáculos como superáveis e/ou analisa seus determinantes para procurar uma solução a algo que lhe parece difícil, buscando alternativas, ele estaria caminhando para um nível superior de desenvolvimento.

A própria concepção do que é tido como conflito para um sujeito pode determinar seu modo de agir diante da situação. Supõe-se que a experiência dos licenciandos nos estágios pode gerar conflitos que são vistos como obstáculos intransponíveis para alguns deles. 0 aluno, assim, procura basear-se somente em rotinas observadas e em receitas prontas, sem procurar suas próprias soluções. Desse modo, é provável que ele imite atitudes dos professores mais experientes, passando, assim como apontado por Imbérnon (1994) para professores novatos, a um conhecimento estratégico espontâneo, ou seja, em que não há uma reflexão sobre os condicionantes da situação. Desenvolve-se uma prática empiricista, de cópia, sem espaço para inovação.

É possivel, ainda, que o licenciando minimize ou negue a existência de um conflito, de modo que sua ação não será modificada. Não perceber um conflito pode significar que não se problematiza a situação ou sua forma de pensar sobre ela, o que dificulta a construção da docência. Situações hierarquizadas e de submissão do docente a possíveis ações repressivas presentes no sistema escolar, por exemplo, podem não ser tidas como geradoras de um conflito (negação do problema) para alguns sujeitos, pois estão naturalizadas para eles. Embora muitas das decisões que o professor toma no cotidiano sejam "automáticas ou implícitas, pois, em geral, o trabalho normal do professor não se resolve por decisões após reflexões prolongadas" (GIMENO SACRISTÁN, 2000, p. 190), entende-se que é já na licenciatura que esse futuro professor deve ter a oportunidade de refletir sobre o vivido, pois reflexão e análise são fundamentais para a 
capacidade de produzir juízos balizados e optar por uma solução, mesmo que momentânea, para o conflito.

\section{Os conflitos vividos pelos licenciandos entrevistados}

No presente estudo, investigamos o modo como os licenciandos do curso de licenciatura em ciências biológicas de uma universidade pública paulista brasileira concebem os conflitos que podem emergir no momento em que iniciam o estágio, e se - e como - eles resolveriam tais conflitos quando solicitados a julgar situações apresentadas em histórias hipotéticas. 0 objetivo do estudo foi relacionar as formas de conceber os conflitos a indícios de desenvolvimento da profissionalidade em alguns licenciandos durante o curso em questão.

Para isso, foram consultados se gostariam de participar da pesquisa os alunos de uma disciplina com estágios de final de curso. Estes responderam a um questionário com perguntas sobre a licenciatura e nele indicaram se aceitavam participar de uma entrevista em que os conflitos seriam explorados. Vinte e um alunos presentes concordaram em responder ao questionário, e seis deles aceitaram a realização da entrevista, assinando um termo de consentimento. Daqui em diante, tais estagiários serão denominados E1, E2, E3, E4, E5 e E6, a fim de preservar o anonimato. Abordaremos, neste artigo, os resultados das entrevistas, as quais foram gravadas e transcritas para posterior análise.

A entrevista teve duas partes: 1) perguntas sobre os dilemas/conflitos e 2) histórias hipotéticas a serem analisadas pelos entrevistados. Antes ou durante a entrevista, era esclarecido que se buscava perceber quando os entrevistados entendiam encontrar-se diante de um impasse ou dilema (optou-se pelo uso deste termo nas questões da entrevista devido à maior facilidade de compreensão) que os leva a não saber como pensar ou agir em determinados momentos, produzindo uma sensação de angústia ou insatisfação. Foram criadas cinco histórias, arbitradas por dois pesquisadores especialistas na área que utilizavam essa metodologia. Tais histórias procuravam englobar situações ouvidas em relatos de estágio e que refletiam contextos gerados pelos desafios de uma nova configuração profissional, abordando a compreensão de questões como autoridade docente, autonomia profissional, escolhas pedagógicas, concepção e função do professor, profissão docente e seu compromisso profissional. As histórias estão resumidas a seguir:

História 1: 0 aluno estagiário vai dar uma aula para a $6^{\text {a }}$ série e, utilizando leitura e explicação sobre texto bem ilustrado, não consegue obter a atenção dos alunos.

Nessa história, esperava-se que o licenciando reflitisse sobre a escolha metodológica e a prática pedagógica diante de uma situação de desinteresse dos alunos. Entende-se que o principal conflito é sobre como realizar escolhas pedagógicas e aliá-las ao interesse e à aprendizagem dos alunos.

História 2: Os alunos faziam as atividades quando as aulas do estagiário eram observadas pelo professor. Quando este faltou, os alunos mudaram de atitude, conversando muito, sem realizar a tarefa, e o estagiário colocou-os para fora da sala.

Nesse caso, esperava-se que o licenciando refletisse se havia um conflito entre ter autoridade na condição de estagiário e de professor.

História 3: 0 estagiário viu os alunos colando em uma prova dada pelo professor, que não se incomodou. A coordenação da escola decidiu assumir a elaboração das provas sem consultar os professores, sendo que um deles criticou a medida e outro gostou, pois iria trabalhar menos.

Aqui, o conflito possível é relativo à função docente e à autonomia profissional, considerando como atribuição da função docente a elaboração de provas para suas turmas. 
História 4: 0 estagiário buscava preparar aula prática em uma escola sem laboratório. 0 professor da escola disse entender que aquilo não valia a pena e classificou a atitude como furor pedagógico de quem começa a atuar.

A partir dessa história, buscava-se esclarecer a relação entre o exercício da profissão docente e o compromisso profissional, suscitando um conflito entre optar por assumir alternativas metodológicas ajustadas ao contexto e à área disciplinar, tidas como compromisso do professor, e as experiências negativas dos professores experientes no exercício profissional.

História 5: Em uma aula do estagiário, um aluno lhe fez uma pergunta a que ele não soube responder. 0 estagiário respondeu dizendo que professor não tem que saber tudo.

0 que se pretendia, com essa história, era saber se vigora a concepção do professor como detentor absoluto do saber, com a função de expor conhecimentos, e, caso isso ocorra, se tal situação leva a um conflito quanto a como reagir diante da não-detenção desse saber.

Nas perguntas que antecederam as histórias, os estagiários foram indagados se viviam algum dilema no estágio de licenciatura, e todos indicaram a possibilidade de não conseguirem dar aula como um conflito vivido naquele momento. Porém, os motivos alegados para entenderem que essa tensão gerava um conflito foram diferentes entre os entrevistados. As condições de trabalho imediatas que dificultam o ensino foram o principal motivo apontado por E1 e E2 para encararem tal situação como um dilema pessoal, evidenciando centração dos aspectos mais imediatos e aparentes presentes no cotidiano da docência.

Acho que o mais mesmo é dar aula mesmo... passando pelo estágio achei bem cansativo... [...] Quando eu comecei entrei meio em choque com os alunos no laboratório quebrando coisa... [riso] [...] então eu já fiquei meio assim, meu Deus do céu, o que que eu estou fazendo aqui? (E2)
A crença de E1 de que teria dificuldades em dar aula foi reforçada pela professora que a licencianda acompanhava em seu estágio:

Um dilema [...] eu queria saber como eu lidaria com estas crianças, com criatividade. Alguns conseguem, a professora disse "vocês não vão conseguir dar aula sem estar comigo junto”. Ela vai estar junto, semana que vem. [...] Vejo outros professores, eles não conseguem, eles berram, e as crianças berram. (E1)

Para E1, agir sem coerção parece levar ao insucesso da atividade docente dos demais professores. Se tomarmos a acepção de Piaget quando aborda a tomada de consciência, o êxito ou fracasso na ação pode levar à busca das causas do erro e à tomada de consciência. Esse raciocínio - e não simplesmente uma crença fez com que a estagiária chegasse a um conflito: não é possível manter a disciplina e o interesse sem ser coercitivo, e essa opção entra em choque com convicções pessoais sobre como o professor deve agir.

Já para E3, E5 e E6, a preocupação em não conseguir dar aula centra-se no questionamento sobre a própria capacidade e no como fazê-lo, ressaltando a dúvida sobra a maneira de desenvolver uma boa aula (esta compreendida como aula favorecedora da aprendizagem). Quando indagados se havia algum dilema sendo vivido no estágio, E3 e E6 responderam de modo semelhante ao discurso de E5, aqui transcrito:

Eu ainda tenho um pouco de receio de... não de dar aula, de não estar fazendo do melhor modo, assim, sabe. [...] Ou quando pega [...] a gente de 'sopetão' assim, e aí a gente faz uma coisa e não sabia o melhor jeito de como fazer isso, porque a classe, parecia que a gente não estava ali, não tinha ninguém... (E5)

Um grande problema para o estagiário de licenciatura está expresso na fala de E5: 
ser um professor invisivel. A invisibilidade ocorre dentro da aula, pois os alunos - a classe, no depoimento de E5 - ignoravam a presença da estagiária na frente da sala, tentando ensinar. Em alguns casos, a presença do estagiário passa despercebida também na escola. E3 e E5 relatam um quase abandono da instituição, a ponto de, após estagiarem quase um semestre, alguém da equipe escolar perguntar-lhes o que estavam fazendo na escola. Cabe indicar que os estagiários relataram várias situações em que são pressionados a assumir aulas por falta de professor, sem terem-se preparado materialmente (e psicologicamente) para tal naquele dia. Esse absenteísmo do professorado, já indicado por António Nóvoa (1995), é parte de um contexto de estágio tido como potencial gerador de conflito. 0 estagiário invisível é lembrado sempre que o professor vai faltar. Além disso, conforme afirma Pimenta (2005), é preciso ressaltar que o estágio é um momento de aprendizado, devendo-se supor que os estagiários não estão completamente seguros para exercer a função docente.

Para E3, E4 e E5, a decepção com a ação docente é fomentada pelas aulas que acompanhavam, nas quais o professor, invariavelmente, passava a matéria na lousa, raramente a explicando, e os alunos copiavam-na, em uma caricatura do que se entende como ensino tradicional. A não existência de um modelo de docência a servir de orientação é alvo de preocupação nas entrevistas desses três estagiários, pois eles se sentiam desnorteados ao terem que assumir para si um novo modelo de construção da docência. Por exemplo, os maiores conflitos para E4 foram referentes às ações dos professores acompanhados, pois estas não eram aceitas como exemplos válidos para a aprendizagem da docência, além da percepção de dissonâncias entre, por um lado, as convicções do estagiário e, por outro, as orientações ou os saberes da docência apresentados pelos professores experientes:
Ah, eu acho que tem, teve dois casos [de dilemas] assim. Um caso assim [...] a $8^{\text {a }}$ série está chegando do intervalo, chega com aquele alvoroço [...] então, nossa, o que eu não gosto é que a professora chega berrando, sabe? "Fica quieto!". Não sei se um dia como professor eu vou chegar a fazer isso. Mas eu fico pensando: como... fazer também para "pegar" a atenção dos alunos. [...] Uma outra coisa [...] Daí ela falou assim "evita de dar risada para os alunos, não sorrir, porque isso daí tira a seriedade". [...] 5a série, todos crianças... E aí eu falei "Nossa, vou fazer o quê?" (E4)

E1, E2 e E6 entendem que a orientação ou o modelo de docência dos docentes acompanhados é válido: para E1 e E2, tal modelo atua como fonte de repertório e de esquemas de ação como imitação; para E6, como fonte de reflexão, com aceitação/rejeição de ações conforme convicções pessoais da licencianda.

E1, E2 e E3 chegam a relatar terem pensado em desistir da licenciatura no momento dos estágios. Ao que tudo indica, quando os estagiários buscam um nível de envolvimento e reflexão maior sobre as situações de estágio, e quando os conflitos são tidos como desafios a serem enfrentados na profissão docente, há maiores tentativas de integrar o dado aos esquemas de docência de que dispõem e não desistir do curso. Aqueles que buscam e não possuem esquemas de enfrentamento, em não os conseguindo, parecem mais dispostos a elaborá-los do que os alunos que se referem à desistência (três em seis). Desistir seria ação do tipo em que não se tentam regulagens ou enfrentamentos da perturbação; regulagens ${ }^{2}$ já caracterizam um enfrentamento. Segundo Piaget, diante de uma perturbação que gera desequilíbrio,

2- Para Piaget, as ações do tipo saber fazer são controladas por regulagens automáticas, determinadas de fora, sem escolha deliberada do sujeito. Outras exigem a tomada de consciência e a intervenção de regulagens ativas, em que se intervém deliberadamente no processo, com reforços ou correções da ação. 
o sujeito tende a compensá-la mediante regulações que conduzem à retomada da ação, corrigindo a ação inicial ou reforçando-a, com alteração de modo a considerar os resultados. (CHAKUR, 2001, p. 76-77)

Durante a análise das questões iniciais da entrevista, já foi possível perceber que E1 e E2 compreendem e identificam conflitos de forma diferente de E3, E4, E5 e E6. Na análise das histórias hipotéticas, essas diferenças ficaram evidentes, e as respostas comuns entre alguns entrevistados evidenciavam que eles percebiam conflitos de forma semelhante. Foi possivel separar os sujeitos em três níveis, conforme a evolução na forma de responder às perguntas e de encarar os conflitos.

\section{Níveis da construção da profissionalidade durante a formação inicial, conforme enfrentamento dos conflitos}

\section{Nível inicial (1) - imitação acrítica de modelos de docência}

0 aluno busca a imitação do professor que acompanha na escola, com a intenção de obter uma experiência variada necessária para compor um repertório copiado de ação profissional, cujo conhecimento viria apenas da experiência. Trata-se da adesão a uma única opção metodológica em vez de combinar várias opções em um planejamento focado na aprendizagem. 0 papel do professor é o de transmissor do conhecimento, embora contemple flexibilidade para não se postar como detentor absoluto do saber em todas as ocasiões. Além disso, há restrição do conteúdo ao que é apresentado em manuais didáticos, com a valorização do papel do professor no ensino de conteúdos; estes são fragmentados e sem vínculo com a formação para a vida. Observase uma centração em características aparentes/ externas à escola para explicar o comportamento do aluno, as más condições materiais etc., características estas articuladas a certo comodismo diante do que está dado. Tendese à pouca reflexão sobre a ação e à ausência de integração e de coordenação de diferentes aspectos para abordar situações das histórias hipotéticas. Os conflitos supostos nas histórias nem sempre são percebidos como conflitos profissionais, e podem ser resolvidos com medidas heterônomas (por exemplo, chamar diretor em caso de problema com aluno), sem que o estagiário assuma sua parcela de responsabilidade sobre a situação ocorrida. A concepção de professor vem da crença apenas em sua função clássica (dar e cobrar conteúdos), e há a tendência de não enfrentar conflitos, por estes não serem percebidos como tais, ou, se percebidos, de enfrentá-los de forma pontual e heterônoma.

Neste nível, encontram-se E1 e E2. Apresentamos a seguir exemplos que levaram à compilação das características citadas.

No conflito com o coordenador que deseja elaborar a prova pelos professores, somente E1 e E2 sugerem medidas heterônomas, em que o coordenador deve repreender os professores a fim de pressioná-los a fazerem provas mais dificeis, sem mencionarem que a tarefa de avaliar é parte da profissionalidade docente. Por exemplo:

Agora, coordenador preparar as questões também... é complicado. Eu acho que seria mais fácil dar uma "puxa" nos professores, fazer eles elaborarem coisas mais complexas pros alunos [...]. (E2, em resposta sobre a história 3, em que o coordenador passa a elaborar as provas no lugar dos professores; grifos nossos)

Essa estagiária não compreende a situação de submissão em que o professor é colocado na história quando deveria, pelas prerrogativas da profissão, resistir a uma interferência no trabalho docente do porte da retratada no relato. No conflito referente ao compromisso profissional e ao furor pedagógico, E1 e E2 
acomodam-se à explicação do professor experiente da história, para quem desinteresse dos alunos e dificuldade em desenvolver as aulas são suficientes para abandonar práticas que seriam de grande valia para a aprendizagem da área biológica, como a experimentação.

\section{Nível intermediário (2) - reflexão e rejeição do modelo de docência observado e tateamento metodológico}

Neste nível, vemos instalarem-se grandes dilemas ou conflitos, a ponto de E5 parecer em tensão permanente. Tais conflitos convergem para uma investigação da prática educativa e para o tateamento de opções metodológicas que promovam a aprendizagem e despertem o interesse dos estudantes. Para os licenciandos deste nível, todos os problemas vividos, como o desinteresse dos alunos e a indisciplina, podem ser resolvidos com mudanças metodológicas nas aulas. Aqui, inicia-se a compreensão de que as relações entre professores e alunos têm que ser construídas, percebendo-se que o estagiário não tem a mesma autoridade do professor, mas, ao tentar exercê-la, opta pela busca de metodologias compreendidas, por si só, como capazes de organizar e de interessar a classe. Em vez da imitação do professor que o estagiário acompanha na escola, há rejeição total de suas atitudes, sem uma reflexão sobre como a experiência vivida ou a ação daquele professor podem contribuir para sua própria formação, o que se coaduna com um desânimo em relação à escola e ao seu papel formador. Nota-se a crítica ao papel do professor como transmissor do saber, bem como à escola, ao comodismo dos alunos, ao ensino ineficaz e à aprendizagem por meio de mera cópia. 0 desinteresse dos alunos naturaliza-se como algo normal da idade e fruto do tipo de ensino observado, em que reina a aula expositiva e a falta de variedade metodológica, sem conhecimentos contextualizados e relacionados à vida do aluno. Inicia-se a descentração, quando o estagiário busca aspectos do mundo não imediato $\mathrm{e}$ não aparente para explicar situações. Porém, a ambiguidade na análise do papel profissional do professor é evidente, e o estagiário não sabe como agir quando tem que abrir mão de algo que seria prerrogativa do professor. Ele apela às soluções de compromisso (conciliatórias), que visam ceder ao desvio da função do professor, ainda sem ter uma identidade clara, focalizando ações para evitar situações em que o conflito apareça, e não ações de enfrentamento. Por fim, os conflitos voltam-se à prática pedagógica.

Neste nível, encontram-se E3, E4 e, em estágio um pouco mais avançado, E5. Alguns exemplos que justificam essa caracterização são apresentados a seguir.

Em relação ao conflito com o coordenador que deseja elaborar a prova pelos professores, os licenciandos E3, E4 e E5 entendem que a regulação do próprio trabalho deve ser feita pelo professor, por meio de avaliações, mas aceitam partilhar essa regulação com o coordenador, sem que a elaboração de prova seja vista como prerrogativa da função docente, o que denota ambiguidade e solução de compromisso (eles não alteram a situação, mas ajustam-na para evitar maiores conflitos, como contestar o coordenador e/ou reivindicar o direito de elaborar as provas). Por exemplo:

De repente, tudo bem dele concordar que a prova seja feita pelo coordenador, mas eu acho que teria que ter uma participação aí, na verdade não é o coordenador que está na classe [...]. (E5, em resposta sobre a história 3, em que o coordenador passa a elaborar as provas no lugar dos professores)

Cabe ressaltar que, nas políticas neoliberais atuais, cada vez mais as avaliações externas atuam como reguladoras do trabalho docente, e essa perda de controle sobre o próprio trabalho pode ser mais facilmente aceita por futuros professores que assim encarem a partilha da avaliação de suas turmas.

A resposta a seguir mostra tanto a crítica ao papel do professor como transmissor, 
quanto a ampliação para o não imediato na análise desse nível:

Quem está começando [...] você sempre vai com aquela ideia, tudo muito fresco, olha eu quero aquilo. Eu acho que esse furor pedagógico eu ouvi com outras palavras. Você quer mudar o mundo, professores novos querem mudar o mundo. É... eu acho que o comentário dele, é porque ele está tão naquela tradicionalidade, na tradição, ele não consegue mais ter mais forças para inovar [...]. (E3, em resposta sobre a história 4, em que o professor experiente considera furor pedagógico implementar aulas práticas)

As explicações para o desinteresse dos alunos na aula do estagiário não se limitaram ao observável, mas foram atribuídas às características da idade e ao ambiente atual em que vivem, onde a ausência de referenciais e atrativos diversos suplanta a atratividade do conteúdo escolar. 0 tateamento metodológico é claro:

Ah, proporciona [um dilema] porque a questão da indisciplina dos alunos [...] Ele daí vai refletir, será que uma atividade prática, será que organizar os alunos em grupos e proporcionar uma discussão? [...]. (E4, em resposta sobre a história 1 , em que os alunos não prestam atenção na aula do estagiário)

\section{Nível avançado (3) - compreensão da profissão docente e consciência da necessidade de construção de um modelo pessoal para a docência}

Apenas E6 está neste nível. Aqui, o licenciando já busca aprofundar as razões para as situações e as várias dimensões (inclusive políticas) implicadas na prática pedagógica. Ele assume a reflexão sobre a própria prática, sem receio de realizar uma autoanálise e de refazer a rota de enfrentamento. Há busca por esquemas de ação, com reflexão para a incorporação/rejeição de características do modelo de docência observado no professor acompanhado; há corresponsabilização nas situações enfrentadas, não sendo a culpa de um insucesso em aula atribuída a priori aos alunos, à direção ou ao tipo de aula dada. A busca metodológica ocorre, porém, não na forma de tateamento, pois o estagiário avalia para escolher: ele entende que não deve trocar ou abandonar uma atividade (por exemplo, aula experimental) sem avaliar por que esta foi proposta, considerando suas convicções pessoais sobre se tal atividade é pedagogicamente válida para os alunos antes de optar por não desenvolvê-la, independentemente da opinião do professor experiente. Por isso, percebe-se que o estagiário busca referenciar-se no que é o compromisso profissional do professor para tomar decisões metodológicas. Entretanto, na condição de estagiário, ele tem consciência de que não pode desenvolver plenamente sua profissionalidade, embora indique ter condições para isso: opta por zelar pela aprendizagem, manter os alunos em sala, discordar do desvio de função, sem assumir totalmente o papel do professor, que tem as prerrogativas do cargo legitimadas institucionalmente. 0 estagiário se sujeita, por entender sua condição provisória na escola, a agir nos espaços delimitados a ele. Valoriza o professor como agente de mudanças e como responsável pelo comportamento e pela aprendizagem dos alunos, considerando que seu papel deve-se à cooperação da equipe escolar. Os dilemas/conflitos apresentados nas histórias são tidos como inerentes à profissão e encarados de forma positiva, como desafios profissionais. Assim, seu maior conflito é não entender como alguns professores optam por não enfrentá-los.

Apresentamos a seguir algumas passagens que caracterizam o nível avançado:

1) Reflexão como forma inicial de enfrentamento dos conflitos:

Mas se é todo mundo [conversando], aí ele tem que refletir, o problema é com ele mesmo. Alguma coisa está errada ali que não 
está funcionando. (E6, em resposta sobre a história 1 , em que os alunos não prestam atenção na aula)

2) Consciência da necessidade de construção de um modelo próprio de docência:

[...] na verdade, 'realmente, eu não estava preparado', e tentar melhorar para as próximas. [0 estagiário] vai desenvolvendo estas técnicas de trabalho! [...] (E6, em resposta sobre a história 5, em que o estagiário não sabe responder à dúvida do aluno)

3) Clareza no papel/compromisso do professor e na necessidade de desenvolver-se profissionalmente, assumindo os conflitos:

Um tema que ele pode entrar é se ele continua nessa linha, pode ser que ele acredita que aquela é a melhor forma [...] (E6 em resposta sobre a história 1 , em que os alunos não prestam atenção na aula)

Mas aula que eu dei, eu dei do meu jeito, que eu achava interessante. Ia para a lousa, questionando, deixava eles fazerem perguntas. Então eu acho que o meu desafio é me desenvolver e me descobrir como eu seria... estou tendo indícios. E tem coisas que a gente acaba absorvendo de outro professor, porque você vê que é bom. Então eu acho que é desenvolver essa percepção. (E6, em resposta sobre como tem lidado com situações vividas no estágio e se há algum dilema sendo enfrentado)

\section{Considerações finais}

0 estudo aqui apresentado aponta para níveis de construção da docência já na licenciatura.
Sobressai-se, então, um conflito a ser enfrentado nos cursos de licenciatura: como contribuir para que os licenciandos atinjam o nivel mais avançado da profissionalidade (nível 3) ainda durante a formação inicial?

Certo é que a formação inicial, por melhor que seja, pode não conseguir anular ou minimizar os conflitos, mas evidenciá-los e problematizar as situações vividas são forma sde trabalhar os conflitos. É urgente preparar novos docentes para o enfrentamento dos conflitos profissionais; sem isso teremos uma geração de novos professores aptos a sucumbir a toda pressão pela qual passa a profissão, a aceitar a redução de sua ação e de seu status e a partilhar seus compromissos com outros profissionais, que lhes retiram a propriedade de regular o próprio trabalho. É preciso apoiá-los a fim de que tenham instrumentos para buscar suas próprias formas de enfrentamento, o que requer valorizar o preparo intelectual e não só formas práticas de enfrentamento. Tornar os conflitos alvos de reflexão, evidenciando a existência de tensões e explicitando o contexto profissional real em que os professores atuam, é, no entender deste estudo, compromisso das licenciaturas. Para tanto, torna-se fundamental trabalhar em conjunto com as escolas-campo de estágio, a fim de viabilizar uma melhor preparação destas para o desenvolvimento dos estágios. Cabe aos professores orientadores dos licenciandos a vivência do cotidiano escolar junto aos estagiários, tendo os dirigentes e, em especial, os professores experientes o papel de co-formadores; cabe a eles, ainda, incluir, nas discussões dos estágios, a luta por melhores condições profissionais entre as formas de enfrentamento dos conflitos. Apesar de tudo, esse parece um caminho promissor a ser trilhado para aprimorar a formação docente nas licenciaturas. 


\section{Referências}

APPLE, Michel W. Trabalho docente e textos: economia política das relações de classe e gênero em educação. Porto Alegre: Artes Médicas, 1995.

BEN-PERETZ, Miriam; KREMER-HAYON, Lya. The contend and context of professional dilemmas encountered by novice and senior teachers. Educational Review, Birmingham, v. 42, n. 1, p. 31-40, 1990.

BERLAK, Ann; BERLAK, Harold. Dilemmas of schooling: teaching and social change. New York: Methuen \& Co, 1981.

CHAKUR, Cilene R. de Sá Leite. Desenvolvimento profissional docente: contribuições de uma leitura piagetiana. Araraquara: JM Editora, 2001. nov. 2002.

A profissionalidade docente em uma abordagem construtivista. Cadernos de Pesquisa, São Paulo, n. 117, p. 146-176,

0 desenvolvimento profissional de professores das séries iniciais do ensino fundamental. Paidéia, Ribeirão Preto, v. 15, n. 32, p. 397-407, set./dez. 2005.

DIAS-DA-SILVA, Maria Helena G. Frem.; MUZZETI, Luci Regina. Licenciaturas ligth: resultado das lutas concorrenciais no campo universitário? Contexto \& Educação, ljuí, ano 21, n. 75, p. 11-28, 2006.

GATTI, Bernadete Angelina. Os professores e suas identidades: o desvelamento da heterogeneidade. Cadernos de Pesquisa, São Paulo, n. 98, p. 85-90, ago. 1996.

GIMENO SACRISTÁN, José. Consciência e acção sobre a prática como libertação profissional dos professores. In: NÓVOA, António (Org.). Profissão professor. 2. ed. Porto: Porto Editora, 1995. p. 63-88.

0 currículo: uma reflexão sobre a prática. 3. ed. Porto Alegre: ArtMed, 2000.

IMBÉRNON, Francisco. La formación y el desarrollo profesional del profesorado: hacia una nueva cultura profesional. BarceIona: Editorial Graó, 1994.

LAMPERT, Magdalene. How do teachers manage to teach? Perspectives on problems in practice. Harvard Educational Review, Harvard, v. 55, n. 2, p. 178-194, 1985.

MASSABNI, Vânia Galindo. 0 construtivismo do professor: de Piaget às idéias e práticas de professores de ciências. 2005. Tese (Doutorado em Educação Escolar) - Faculdade de Ciências e Letras, Universidade Estadual Paulista "Júlio de Mesquita Filho", Araraquara, 2005.

MIZUKAMI, Maria da Graça Nicolitti. Casos de ensino e aprendizagem profissional da docência. In: ABRAMOVICZ, Anete.; MELLO, Roseli Rodrigues de (Orgs.). Educação: pesquisas e práticas. Campinas: Papirus, 2000. p. 139-161.

NÓVOA, António. Formação de professores e profissão docente. In: (Coord.) Os professores e a sua formação. Lisboa: Dom Quixote, 1992. p. 15-33.

Profissão professor. Porto: Porto Editora, 1995.

PIAGET, Jean. A equilibração das estruturas cognitivas (problema central do desenvolvimento). Rio de Janeiro: Zahar Editores, 1976.

A tomada de consciência. São Paulo: Melhoramentos, 1977.

PIMENTA, Selma Garrido. Formação de professores: identidade e saberes da docência. In: (Org.). Saberes pedagógicos

e atividade docente. 3. ed. São Paulo: Cortez, 2002. p. 15-34.

0 estágio na formação de professores: unidade teoria e prática? 6. ed. São Paulo: Cortez, 2005. 
TARDIF, Maurice. Saberes docentes e formação profissional. 3. ed. Petrópolis: Vozes, 2002.

VILLA, Aurélio. La formación del profesorado em la encrucijada. In: docente. Madrid: Narcea, 1988. p. 24-38.

(Coord.) Perspectivas y problemas de la función

ZABALZA, Miguel A. Diários de aula: um instrumento de pesquisa e desenvolvimento profissional. Porto Alegre: Artmed, 2004.

ZEICHNER, Kenneth M. A formação reflexiva de professores: idéias e práticas. Lisboa: EDUCA, 1993.

Recebido em: 08.06.2010

Aprovado em: 10.12.2010

Vânia G. Massabni é docente do Departamento de Economia, Administração e Sociologia da Escola Superior de Agricultura "Luiz de Queiroz" da Universidade de São Paulo e atua nos cursos de Licenciatura em Ciências Agrárias e em Ciências Biológicas. 